\title{
Exploring the Effects of a Mindfulness Program for Students of Secondary School
}

\author{
Clemente Franco, University of Almeria, Spain \\ Israel Mañas, University of Almería, Spain \\ Adolfo J. Cangas, University of Almería, Spain \\ José Gallego, University of Almería, Spain
}

\begin{abstract}
This study analyzes the effects of a mindfulness program on a group of students in the first year of Compulsory Secondary Education from three public schools. A total of 61 students participated. A group comparison design (randomized controlled trial) with pretest-posttest measurement was used on an experimental and a control group. The statistical analyses show a significant improvement of academic performance, as well as an increase in all self-concept dimensions and a significant decrease in anxiety states and traits. These results are in agreement with other studies that have found mindfulness programmes to be effective in the educative system. The importance of mindfulness techniques in the educative system is also discussed.
\end{abstract}

Keywords: $\quad$ Academic Performance, Anxiety, Mindfulness, Students, Self-Concept

\section{INTRODUCTION}

Many studies have established a causal relationship between a student's academic self concept and academic performance, to the point where academic self-concept is considered the basis of a student's future success or failure (Marsh, 1990; Skaalvik \& Hagtvet, 1990), finding that a high self-concept contributes to scholastic success, which in turn favors development of a positive self-concept (Liu, Kaplan, \& Risser, 1992; Roberts, Sarigiani, Peterson, \& Newman,

DOI: $10.4018 / \mathrm{jksr} .2011010102$
1993). Corbière, Fraccaroli, Mbekou, and Perron (2006) also found a significant and positive correlation between academic self-concept, academic interest, and academic achievement. Other studies show that the higher a student's positive self-concept is, the better the conditions motivating study (anxiety, concentration and aptitude for school work) and the stronger study and deep-learning strategies used, which also makes positive self-concept favor the student's use of more cognitive learning strategies, thereby facilitating more profound, elaborate information processing (González-Pienda et al., 2002; Núñez et al., 1998). 
This active involvement in the learning process increases when the student feels selfcompetent believes in his own abilities and has high expectations for self-effectiveness (Millar, Behrens, \& Greene, 1993). This also increases when tasks are evaluated and when he feels responsible for the learning goals, which improves his academic performance (Núñez, GonzálezPienda, García, González-Pumariega, \& García, 1995). It has also been demonstrated that high levels of stress in the academic environment cause attention and concentration deficits, difficulties in memorizing and problem solving, deficits in study skills, low productivity and academic performance (Pérez, Martín, Borda, \& Del Río, 2003).

Anxiety is also one of the main factors negatively affecting academic performance. Carbonero (1999) says that anxiety can lead to deterioration of academic performance because the student focuses on negative thoughts about his abilities more than on the task itself. Rivas (1997) notes that students with high anxiety levels tend to focus their attention on how hard the task is, on their academic failures and on their lack of personal skills. High levels of anxiety therefore tend to alter the student's psychological functioning to the extent that memory, attention and concentration are affected and diminished, disturbing academic performance, as this requires attention, concentration and sustained effort to be maintained at an optimum, effective level (Rains, 2004). Research, such as the studies by Del Barrio (1997) and Mestre (1992) has demonstrated both an increase in emotional disorders (anxiety and depression) in teenagers, as well as the relationship between these disorders and the student's academic performance. Therefore, promoting and training the affective strategies based on self-control, techniques increasing attention and improving self-knowledge, can exert a positive effect on the student's academic performance (Camero, Martín, \& Herrero, 2000).

Psychology is currently employing meditation under the label mindfulness as an intervention technique or clinical method. Mindfulness has been demonstrated to be ef- fective in a number of medical, psychological and educational problems, so it has captured the attention of psychology and has been included in a wide variety of psychological interventions and therapies, whether explicit or implicit, exclusive or integrated as one more component in a treatment program composed of a multitude of clinical elements or techniques (Baer, 2003; Germer, Siegel, \& Fulton, 2005; Hayes \& Feldman, 2004; Hayes, Follete, \& Linehan, 2004). Mindfulness in contemporary psychology has been adopted as an approach for increasing awareness and responding skilfully to mental processes that contribute to emotional distress and maladaptive behaviours (Bishop et al., 2004). The practice of mindfulness teaches one to approach internal experiences with curiosity and acceptance, which allows for intensive self-observation without judgement, elaboration, or attempts to fix or change the experience. Mindfulness has been described as a process of bringing a certain quality of attention to moment-by-moment experience (Kabat-Zinn, 1990).

Meditation or mindfulness techniques, have shown their effectiveness in improving psychological discomfort in its various forms of anxiety (Barnes, Treiber, \& Davis, 2001; Epply, Abraham, \& Shear, 1989; Kabat-Zinn et al., 1992), depression (Teasdale et al., 2000), insomnia (Jacobs, Benson, \& Friedman, 1993), and general wellness (Brown \& Ryan, 2003). Other effects of meditation related more directly to stress and anxiety are reduced nervousness, worry and emotional discomfort, and increased muscular relaxation and emotional calm (Mañas, Luciano, \& Sánchez, 2008; Mañas, Sánchez, \& Luciano, 2008). It also diminishes cortisol levels (MacLean et al., 1994; Sudsuang, 1991) and blood lactate (Solberg, Halvorsen, \& Holen, 2000), which, among others, are markers of stress and anxiety.

Meditation also causes biochemical changes in the brain associated with more positive emotions and improvements in the organism's immune function (Davidson et al., 2003; Solberg et al., 2000; Solberg, Halvorsen, Sundgot-Borgen, Ingjer, \& Holen, 1995). Many 
studies have demonstrated an increase in activity in the left frontal lobe which is where positive emotions are stored and managed, at the same time it reduces functioning of the right side (Goleman, 2003; Austin, 1998). It has also been verified that persons who use the left side of the brain eliminate negative emotions and tension in a shorter time, at the same time as emotions such as anger and anxiety are reduced (Brefczynski-Lewis, Lutz, Schaefer, Levinson, \& Davidson, 2007; Davidson et al., 2003). The healthy effects of meditation are many and varied (Arias, Steinberg, Banga, \& Trestman, 2006; Brown \& Ryan, 2003; Brown, Ryan, \& Creswell, 2007; Grossman, Niemann, Schmidt, $\&$ Walach, 2004).

The meditative state is different from relaxation or sleep, because during meditation, alertness increases instead of diminishing (Jevning, 1988; Jevning, Anand, Biedebach, \& Fernando, 1996). In fact, meditation has been erroneously confused with a type of relaxation, but the EEG patterns have demonstrated that meditation and relaxation cause different physiological effects, as during meditation the mind is relaxed and aware at the same time (Dunn, Hartigan, \& Mikulas, 1999). According to Campagne (2004), while relaxation techniques are based on training in confronting stressful events by controlling the effects of stress, meditation trains in confronting stressful events, and removing their stressful nature, while reducing blood cortisol levels. That is, while relaxation techniques employ willpower and concentration to achieve a state of relaxation, meditation also uses willpower and concentration, not to relax, but to stay alert and lose all notion of thought content, without losing awareness, or mental clarity.

One of the characteristics of meditation is the ability to project a single set of signals at the same time, such as breathing or thoughts. This produces changes in the physiological structure of the organism, which at the same time results in a tendency towards normalizing reactions and to more healthy, relaxed physiological behavior. In this way, tension and anxiety are reduced, the heart beat and metabolism are slowed and there is an increase in attention and ability to
concentrate(LeShan, 2005). Some studies have found that with practice, meditation is able to train mental activity and processes, strengthening all the cognitive abilities upon acquiring the skill of methodically exercising mental attention and concentration (Jha, Krompinger, \& Baime, 2007; Valentine \& Sweet, 1999). Meditation increases the ability to focus attention and ignore distractions, and improves cognitive performance in demanding situations, tension and concentration (Solberg, Berglund, Engen, Ekeberg, \& Loeb, 1996; Sugiura, 2004), as for example, during an exam. Furthermore, meditation has also been related to improvements in self-concept (Trumbulls \& Norris, 1982; Van der Berg \& Mulder, 1976).

In the sphere of education, mindfulness has also been demonstrated effective in different ways. Barnes, Bauza, and Treiber (2003) used a meditation program with students with classroom behavior problems, and found that their class attendance and school behavior improved. Barragán, Lewis, and Palacio (2007) found that mindfulness intervention in a sample of university students improved their ability to focus and sustain attention, to follow a stimulus closely and to manage distraction. More specifically, meditation has been directly related to increasing and improving academic performance. Chang and Hierbert (1989) showed how primary students significantly improved their schoolwork after mindfulness intervention. Cranson, Orme-Johnson, Gackenbach, Dillbeck, Jones, and Alexander (1991) demonstrated that university students that practiced mindfulness twice a day increased their academic performance. León (2008) found a significant relationship between the levels of mindfulness and academic performance in secondary education students. Finally, Beaucheim, Hutchins, and Patterson (2008) carried out a study in which they applied meditation to a group of 34 students with learning problems and low academic performance, and found that after training, this group significantly improved its academic performance, its social skills and diminished trait anxiety. 
Recently, a mindfulness program called 'Meditación Fluir' (Franco, 2007, 2009b) has also been effective in the field of education in different ways. For example, by reducing stress perception in students of teacher education (Franco, 2009b), increasing the verbal creativity levels in a group of high school (Franco, in press), reducing levels of educational stress and of the days taken off work on sick leave, in teachers of obligatory secondary education (Franco \& Mañas, 2009), as well as psychological distress (Franco, Mañas, Cangas, Moreno, $\&$ Gallego, in press), or by improving the values in a sample of university students (Franco \& Navas, in press). However, the efficacy of Meditación Fluir has still not been examined on the variables academic performance, selfconcept and anxiety.

To summarize, the literature available seems to indicate that stress and anxiety, as well as self-concept, play a decisive role in academic performance. Furthermore, meditation has been demonstrated to reduce stress and anxiety, at the same time it leads to improved cognitive skills, such as attention, memory and concentration, as well as academic performance. Therefore, the main goal of this study is to examine whether the application of the meditation program Meditación Fluir, which has demonstrated to be effective in the field of education in different ways, could also be effective in improving academic performance and self-concept, and in reducing the levels of anxiety in secondary school students.

\section{METHOD}

\section{Participants}

A total of 61 1st-year high school students, 31 male and 29 female, between the ages of 16 and18 $(M=16.75 ; S D=0.83)$, in the first year of Enseñanza Secundaria Obligatoria (Compulsory Secondary Education) at three public schools in the province of Almería, Spain, participated in this study.

\section{Materials}

Academic performance. To evaluate their academic performance, their grades in the subjects studied by all of the students in the first year of high school (i.e., Spanish language and literature, foreign language and philosophy) were added up, and this score was then divided among the number of subjects. This provided academic performance rates for each of the subjects as well as a total academic performance rate.

Cuestionario de Autoconcepto (Self-Concept Questionnaire), Form A(Musitu, García, \& Gutiérrez, 1994). This 36-item selfadministered questionnaire measures four dimensions of self-concept (academic, social, emotional and family) and gives a total score. This questionnaire's high internal consistency has an alpha of 0.82 .

Cuestionario de Ansiedad Estado-Rasgo (Spanish version of the State-Trait Anxiety Inventory (STAI) published by TEA) (Spielberger, Gorsuch, \& Lushene, 1988). This questionnaire is composed of two scales that measure two independent concepts of anxiety, state and trait. It is made up of 40 items (20 for each scale) in which the subjects must evaluate how they feel generally (trait anxiety), and at the moment (state anxiety) on a 0-3-point Likert scale. The coefficient of internal consistency is 0.91 and 0.94 for the trait-anxiety and state-anxiety scales, respectively, and test-retest reliability is 0.81 for trait anxiety and 0.40 for state anxiety.

\section{Design and Procedure}

To analyze the effects of the mindfulness program (independent variable) on academic performance, students' self-concept and anxiety (dependent variables), a group comparison design (randomized controlled trial) with pretest-posttest measurement was used on an experimental and a control group. 
First place, three schools in the province of Almería were chosen at random. Then the principals of those schools were contacted to offer them an extracurricular workshop on meditation and relaxation techniques for their first year high school students free of charge. A total of 67 students signed up for the course, of which only 61 were used for the study, since the results from students who said they had had some experience with a relaxation technique, such as yoga, tai-chi, etc., were disqualified. Prior to their participation, informed consent was received from all parents or tutors.

Sixty-one subjects were allocated at random into to groups, 30 were in the control group and the remaining 31 were in the experimental group. The students did not receive any kind of compensation for participating.

Once the two groups had been formed, we proceeded to pretest evaluation of anxiety and self-concept levels in each group using the Cuestionario de Ansiedad Estado-Rasgo (StateTrait Anxiety Inventory) and the Cuestionario deAutoconcepto (Self-ConceptQuestionnaire), respectively.

For the academic performance score, we contacted the students' tutors, who provided us with their first-quarter grades in the academic year in progress.

Once this first measurement was found, the subjects in the control group were told that the workshop would begin in three months and the intervention program was begun with the participants in the experimental group.

The meditation program was given in 1 hr 30 min session per week for 10 weeks. The intervention program consisted of learning the mindfulness technique called Meditación Fluir (Franco, 2007, 2009a) and practicing daily for 30 minutes. The main goal of this technique is not to try and control thoughts or change them or replace them with others, but on the contrary, just let them alone, and accept any idea that might appear or emerge spontaneously, developing a state of full attention to this mental activity, while being aware that they are transitory and nonpermanent.
The practice of Meditación Fluir consists of repeating a word, or mantra, with a free, open mentality, while directing attention toward the abdomen and noticing how air goes in and out while breathing, but not trying to change or alter respiration itself, since only awareness of how it happens naturally and without effort is necessary. Therefore, what is essential when Meditación Fluir is practiced is not the thoughts in themselves, but the awareness of them without evaluating, judging or analyzing them, and just watching how they appear and disappear, and letting them go by.

In each of the 10 sessions, in addition to learning and practicing the Meditación Fluir technique, a variety of Acceptance and Commitment Therapy (ACT; Hayes, Stroshal, \& Wilson, 1999) metaphors and exercise are used along with tales from the Zen Tradition (Deshimaru, 2006) and from the Vipassana meditation (Hart, 1994) in order to stress and reinforce the assumption of how the attempt to control annoying and unpleasant private events only makes them chronic and aggravates the psychological discomfort they cause, and therefore, the best thing to do is let them flow freely.

Finally, body-scan exercises (Kabat-Zinn, 1990, 1994) were another part of the meditation program learned and practiced during all 10 sessions. The body-scan is a meditation technique where attention is brought in systematic fashion to different regions of the body -from head to foot and from foot to head- and then, in an expansive awareness of the entire body; without judgement, or attempts to fix or change anything (e.g., body sensations, mental reactions, etc.), being present, moment to moment.

At the end of the mindfulness training, the subjects' academic performance, self-concept and anxiety were evaluated again in both the control and experimental groups, under the same conditions and with the same instruments as those used before intervention.

When the study was completed, the meditation course was given to the control group. All the subjects participating in the study were informed of its purpose at the end of it, and 
Table 1. Pretest and posttest means and standard deviations in the experimental and control groups for academic performance, self-concept and anxiety

\begin{tabular}{lcccccccc} 
& \multicolumn{3}{c}{ PRE-TEST } & & \multicolumn{3}{c}{ POST-TEST } \\
\hline & Control & \multicolumn{2}{c}{ Experim. } & Control & Experim. \\
\hline Variable & $M$ & $S D$ & $M$ & $S D$ & $M$ & $S D$ & $M$ & $S D$ \\
\hline Philosophy & 5.45 & 2.35 & 5.32 & 1.82 & 5.15 & 2.58 & 6.95 & 1.31 \\
Spanish Language & 5.80 & 1.98 & 4.58 & 1.57 & 5.75 & 2.22 & 7.21 & 1.27 \\
Foreign Language & 5.10 & 1.74 & 5.21 & 2.09 & 4.75 & 2.14 & 6.74 & 1.93 \\
Acade. Performance & 5.44 & 1.67 & 5.03 & 1.35 & 5.21 & 1.80 & 6.95 & 1.09 \\
Self- Con. Academic & 22.5 & 2.39 & 23.3 & 3.14 & 22.9 & 3.01 & 26.9 & 2.98 \\
Self-Concept Social & 12.6 & 1.98 & 13.5 & 1.46 & 12.4 & 2.13 & 14.4 & 2.81 \\
Self-Con. Emotional & 17.6 & 2.83 & 18.4 & 2.89 & 16.8 & 2.43 & 22.9 & 1.87 \\
Self-Concept Family & 14.6 & 2.51 & 15.3 & 1.63 & 14.8 & 1.76 & 16.5 & 2.09 \\
Self-Concept Total & 67.4 & 4.87 & 70.5 & 5.52 & 66.7 & 4.64 & 80.3 & 6.46 \\
State Anxiety & 20.3 & 9.81 & 16.0 & 8.55 & 21.2 & 9.61 & 12.8 & 6.17 \\
Trait Anxiety & 23.5 & 8.83 & 21.5 & 8.10 & 15.6 & 9.67 & 15.6 & 5.77 \\
\hline & & & & & & & & \\
\hline
\end{tabular}

written consent was requested from their parents for the use of the data acquired, guaranteeing to maintain all data confidential and anonymous.

\section{RESULTS}

All of the statistical analyses were done using the SPSS ver. 15.0 statistics package.

Table 1 shows the pretest and post test measurements and standard deviations in academic performance, self-concept and anxiety for the experimental and the control groups. To find out whether there were any statistically significant differences between the pretest and posttest measurements, the Student's t-test for related samples was used on both the experimental and control group. The control and experimental groups were also analyzed for differences before and after intervention in both groups with the Student's t-test for independent samples. The Student's $t$ was employed because it is the statistical technique recommended in quasiexperimental pre-test/post-test studies when the group to compare are only two (control and experimental) due to its sensibility and capacity of discrimination to little samples (Rial \& Varela, 2008).

The statistical analysis of the differences in pretest scores between the experimental and control group showed that there were no significant starting differences between the groups for the variables studied (see Table 2).

Differences in experimental and control group posttest measurements were analyzed to find whether there had been significant improvement in the experimental group over the control group after intervention. Statistically significant differences appeared between the groups in all the variables analyzed: total academic performance $(t=3.62 ; p=.001)$, and each subject (philosophy $[t=2.71 ; p=.01]$, Spanish language and literature $[t=2.51 ; p<.05]$, and foreign language $[t=3.02 ; p<.005])$; total self-concept $(t=10.1 ; \mathrm{p}<.001)$, and in all of the self-concept dimensions (academic $[t=3.62 ; p=.001]$, social $[t=3.97 ; p=.001]$, emotional $[t=8.73 ; p<.001]$, and family $[t=2.72 ; p=.001])$; and, finally, state anxiety $(t=3.22 ; p<.005)$ and trait anxiety $(t=3.14 ; p<.005)$ (see Table 2). 
Table 2. Student's t-test for independent samples of the pretest and posttest differences between the experimental and control groups for academic performance, self-concept and anxiety

\begin{tabular}{lcccc}
\hline & \multicolumn{2}{c}{ PRE-TEST } & \multicolumn{2}{c}{ POST-TEST } \\
\hline Variable & $t$ & $p$ & $t$ & $p$ \\
\hline Philosophy & .198 & .844 & 2.71 & $.010^{* * *}$ \\
Spanish Language & 2.06 & .166 & 2.51 & $.017^{* * * *}$ \\
Foreign Language & .179 & .859 & 3.02 & $.004^{* *}$ \\
Acade. Performance & .846 & .403 & 3.62 & $.001^{*}$ \\
Self- Con. Academic & .858 & .396 & 4.86 & $.001^{*}$ \\
Self-Concept Social & 1.56 & .127 & 3.97 & $.001^{*}$ \\
Self-Con. Emotional & .895 & .337 & 8.73 & $.001^{*}$ \\
Self-Concept Family & .973 & .227 & 2.72 & $.010^{* * *}$ \\
Self-Concept Total & 1.87 & .098 & 10.1 & $.001^{*}$ \\
State Anxiety & 1.45 & .154 & 3.22 & $.003^{* *}$ \\
Trait Anxiety & .725 & .473 & 3.14 & $.003^{* *}$ \\
\hline
\end{tabular}

Note: $* p=.001 ; * * p<.005 ; * * * p=.01 ; * * * * p<.05$

Table 3. Student's t-test for pretest-posttest differences in the experimental and control groups, and Cohen's $d$ in the experimental group for academic performance, self-concept and anxiety

\begin{tabular}{lcccccc}
\hline & \multicolumn{3}{c}{ CONTROL } & \multicolumn{3}{c}{ EXPERIMENTAL } \\
\hline Variable & $t$ & $p$ & $d$ & $t$ & $p$ & $d$ \\
\hline Philosophy & .922 & .368 & .121 & 7.03 & $.001^{*}$ & 1.03 \\
Spanish Language & .127 & .900 & .023 & 9.12 & $.001^{*}$ & 1.85 \\
Foreign Language & .907 & .376 & .180 & 4.78 & $.001^{*}$ & .760 \\
Acade. Performance & 1.13 & .271 & .132 & 12.5 & $.001^{*}$ & 1.57 \\
Self- Con. Academic & .857 & .402 & .147 & 5.33 & $.001^{*}$ & 1.17 \\
Self-Concept Social & 1.15 & .262 & .097 & 3.39 & $.003^{* *}$ & .400 \\
Self-Con. Emotional & 1.58 & .190 & .304 & 8.10 & $.001^{*}$ & 1.85 \\
Self-Concept Family & .448 & .659 & .092 & 2.11 & $.049^{* * *}$ & .640 \\
Self-Concept Total & .892 & .384 & .147 & 8.63 & $.001^{*}$ & 1.63 \\
State Anxiety & 1.72 & .100 & .092 & 3.89 & $.001^{*}$ & .430 \\
Trait Anxiety & .254 & .802 & .227 & 6.86 & $.001^{*}$ & .840 \\
\hline
\end{tabular}

Note: ${ }^{*} p=.001 ;{ }^{* *} p<.005 ; * * * p<.05$ 
The Student's t-test for related samples was applied to find out whether there were significant differences between the pretest and posttest scores in the control group, and no significant differences appeared between pretest and posttest scores on any of the variables analyzed in this group (see Table 3).

The Student's t-test for related samples was also applied to find whether there were any significant pretest-posttest differences in the experimental group scores, and statistically significant differences were again found in all of variables analyzed: academic performance $(t=12.5 ; p<.001)$, and all of the subjects (philosophy $[t=7.03 ; p<.001]$, Spanish language and literature $[t=9.12 ; p<.001]$, and foreign language $[t=4.78 ; p=.001])$; total self-concept $(t=8.63 ; \mathrm{p}<.001)$ and in its different dimensions (academic $[t=5.33 ; p<.001]$, social $[t=3.39$; $p<.005]$, emotional $[t=8.10 ; p<.001]$, and family $[t=2.11 ; p<.05])$; and finally, state anxiety $(t=3.89 ; p=.001)$ and trait anxiety $(t=6.86$; $p<.001)$ (see Table 3).

The Cohen's $d$ (1988) was used for evaluating the effect-size of the change in the control group and in the experimental group after intervention. Over 1.5 indicated very large changes, from 1 to 1.5 large and from .5 to 1 medium. In Table 3, Cohen's $d$ scores demonstrate that there were not any important changes in the control group, all Cohen's $d$ scores were between .0 and .3 . However, in the experimental group there were very large changes in Spanish language $(d=1.85)$, emotional self-concept $(d=1.85)$, total self-concept $(d=1.63)$, and academic performance $(d=1.57)$. Large changes appear in academic self-concept $(d=1.17)$, and philosophy $(d=1.03)$. There were medium effect changes in trait anxiety $(d=.84)$, foreign language $(d=.76)$, and family self-concept $(d=.64)$. And finally, there were small changes in state anxiety $(d=.43)$ and social self-concept $(d=.40)$ (see Table 3 ).

The experimental group was also divided into three subgroups by pretest score (high, medium and low scores) on each of the variables (total academic performance, total self-concept, state anxiety and trait anxiety) to analyze the effects of the intervention program in more detail. Tables 4 and 5 show the pretest and posttest mean scores and standard deviations for each variable for the high, intermediate and low-score subgroups.

Table 4. Pretest means and standard deviations for the experimental group with high, medium and low academic performance, self-concept, and trait and state anxiety

\begin{tabular}{|c|c|c|c|c|c|c|}
\hline & $\mathrm{Hiş}$ & & Med & & Lo & \\
\hline Variable & $M$ & $S D$ & $M$ & $S D$ & $M$ & $S D$ \\
\hline Academic Performance & 6.52 & .597 & 5.38 & .271 & 3.83 & 1.07 \\
\hline Self-Concept Total & 77.5 & 2.66 & 69.5 & .548 & 65.5 & 2.63 \\
\hline State Anxiety & 25.1 & 3.65 & 17.0 & 1.82 & 5.67 & 3.98 \\
\hline Trait Anxiety & 29.2 & 4.23 & 21.6 & 2.25 & 12.5 & 5.28 \\
\hline
\end{tabular}


Then the Cohen's $d$ was calculated to analyze the effect size of the change caused by the intervention program in each of these subgroups. As observed in Table 5, all three subgroups underwent very large changes in academic performance after the meditation program, with the largest effects in the subgroup with medium academic performance $(d=3.05)$, followed by the subgroup with a high score $(d=2.49)$ and finally, the subgroup with a low score $(d=1.67)$. There were also very large changes in total self-concept in all three groups, where this time the largest effects are found in the subgroup with the originally low self-concept $(d=5.12)$, followed by the medium-score group $(d=2.78)$ and, finally, by the high-score group $(d=2.04)$. Subjects who started out with a high score in state-anxiety on the pretest benefited most after the meditation intervention, and the effect-size of the intervention program in this group is very large $(d=1.95)$. In the subgroup with an originally low state anxiety, the change undergone between pretest and posttest is large $(d=1.11)$, with no change in the subgroup with an originally low score in this variable $(d=0.00)$. Finally, there were large changes in trait anxiety in the subgroup with medium pretest scores, $(d=1.44)$, medium changes in the subgroup with originally low scores $(d=.730)$, and small changes in the subgroup with an originally high score on this variable.

\section{DISCUSSION}

The results show that, in the first place, the academic performance of the participants in the experimental group improved significantly more than the control group, and furthermore, this improvement affected all three subjects (philosophy, Spanish language and literature and foreign language). We can further state that the intervention program also caused important changes in total self-concept, the second variable analyzed, as well as in its various dimensions (academic, social, emotional and family). Finally, the meditation program significantly reduced state and trait-anxiety levels. Therefore, it is possible to conclude that Meditación Fluir can also be effective in improving academic performance and self-concept, at the same time as reducing the levels of anxiety in a sample of adolescent students. These results are in agreement with those found by other studies that show the beneficial effects of practicing meditation on academic performance (Beaucheim et al., 2008; Chang \& Hierbert, 1989; Crason et al., 1991; León, 2008; Sugiura, 2003), and relate them to improvement in self-concept (Trumbulls, \& Norris, 1982; Van der Berg \& Mulder, 1976), and lowered anxiety levels (Barnes et al., 2001; Beaucheim et al., 2008; Epply et al., 1989; Kabat-Zinn et al., 1992).

The results obtained were quite similar to those reported by Beaucheim et al. (2008):

Table 5. Posttest means, standard deviations and Cohen's d for the experimental group with high, medium and low academic performance, self-concept, and trait and state anxiety

\begin{tabular}{lccccccccccc} 
& \multicolumn{1}{l}{ High } & \multicolumn{4}{c}{ Medium } & \multicolumn{4}{c}{ Low } \\
& & & \multicolumn{1}{c}{} & & & & & & \\
\hline Variable & $M$ & $S D$ & $d$ & $M$ & $S D$ & $d$ & $M$ & $S D$ & $d$ \\
& & & & & & & & & \\
\hline Acade. Performance & 8.12 & .725 & 2.49 & 7.00 & .715 & 3.05 & 6.18 & .874 & 1.67 \\
Self-Concept Total & 82.8 & 2.56 & 2.04 & 79.5 & 5.05 & 2.78 & 79.0 & 2.64 & 5.12 \\
State Anxiety & 19.0 & 2.60 & 1.95 & 13.7 & 3.77 & 1.11 & 5.67 & 2.25 & 0.00 \\
Trait Anxiety & 20.0 & 3.16 & .406 & 17.0 & 4.00 & 1.44 & 9.17 & 3.60 & .730
\end{tabular}


both studies demonstrated improved academic performance and diminished levels of state and trait anxiety in a group of adolescents in a natural environment. However, there are some important differences between both studies. Firstly, apart from academic performance and self-concept, a third variable was analyzed in each: self-concept in the present study versus social skills in the Beaucheim study. Secondly, the sample in Beaucheim's study was smaller (i.e., 34) and was composed of adolescents diagnosed with learning disabilities and low academic performance, whereas in this study the sample was bigger (i.e., 61) and the participants were adolescents without learning disabilities or low academic performance. Thirdly, $53 \%$ of the 34 students from the Beaucheim study had had some previous experience with meditation and/or relaxation training and they participated. However, in this study only $9 \%$ of the 67 students had had any previous experience with meditation and/or relaxation techniques and so were disqualified, that is, they did not participate. Next, the Beaucheim study used a pre-post no control-design, whereas this study employed a randomized controlled trial, with pre-post measurements for two groups, an experimental and a control.

Considering the previous three differences, the external and internal validity of the current study could have been higher. That is, the outcomes obtained could be generalized to a greater number of people (not only to those with learning disabilities and/or low academic performance) and attributed in a stronger way to the training program or intervention (i.e., the cause or the independent variable) and not to other possible causes or variables (e.g., effects of the previous experience). Finally, the mindfulness techniques employed in the mindfulness training program by Beaucheim were exclusively those from the meditation-based stress reduction (MBSR) program (Kabat-Zinn, 1994). However, the mindfulness training program used in this study included, in addition to usual mindfulness techniques (i.e., Meditación Fluir and bodyscan), another of Acceptance and Commitment Therapy (ACT). That is, the components of both programs were different. Consequently, the most important original contributions of this study were, on the one hand, to examine the effectiveness of mindfulness, specifically the program Meditación Fluir, on the variables academic performance, self-concept and anxiety at the same time, and the other hand, to employ traditional mindfulness techniques simultaneously with others from ACT.

ACT efficacy and effectiveness has been empirically demonstrated on a wide variety of problems both medical and psychological and also in organizational settings and topics (Hayes \& Strosalhl, 2004; Hayes, Luoma, Bond, Masuda, \& Lillis, 2006). Perhaps the use of certain ACT exercises, metaphors and paradoxes positively affected certain variables such as breaking the 'cognitive defusion' by developing psychological flexibility, or for example, abandoning control of private events (e.g., thoughts, feelings, bodily sensations, etc.) and promoting their acceptance (Blackledge, 2007; Hayes \& Feldman, 2004; Hayes \& Stroshal, 2004; Hayes et al., 1999). Nevertheless, in order to isolate the relative effect of ACT techniques, it would be necessary to carry out controlled studies comparing trainings in mindfulness with and without ACT components. Further investigations are clearly necessary to clarify this issue.

Campagne (2004) believes that training both attention and distraction through the practice of meditation leads to greater control over the constant interference that makes the mind a "noisy place" and does not allow one to think clearly, or distinguish what is essential from what is irrelevant. Meditation may be considered an effective technique for controlling chaotic and repetitive thought which may limit cognitive abilities and also personal balance. Therefore, one of the main benefits of continually practicing meditation is the cessation of the frenetic, chaotic rhythm of thoughts that surge automatically, without any control, as that constant flow of uncontrolled thoughts distracts and impedes one's capacity for attention and concentration (Austin, 1998). Mindfulness may incorporate other elements or components which might explain the change 
in academic performance, such as training in certain cognitive skills (such as attention, concentration and memory), a feeling of wellness and emotional balance -not just relaxation-, an improvement in self-control, which could favor optimal execution in tense and demanding situations, such as those typical during an exam, improvements in own self-concept, etc.

Between-group differences found for the various dimensions of school performance analyzed were, in order of importance, the following: in subjects, foreign language $(p=<.005)$, philosophy $(p=.01)$ and, last, Spanish language and literature $(p<.05)$. In the self-concept dimensions, the differences were most significant in the emotional component $(p<.001)$, followed by academic and social $(p=.001)$, and somewhat less in the family dimension $(p=.01)$. The differential effect of the intervention on variables may also be observed in a comparison of the experimental group's pretest and posttest scores using the Cohen's $d$. There were very large effects on the total academic performance $(d=1.57)$ and total self-concept $(\mathrm{d}=1.63)$ variables, large effects on trait $(d=.84)$ and less on state anxiety $(d=.43)$.

We may therefore suggest a certain differential effect of the meditation program on the variables analyzed in this study and we propose the need for future research that can isolate the differential effects of meditation more clearly, not only between variables (e.g., academic performance and self-concept), but also on the dimensions within a same variable (e.g., in the various subjects). It is reasonable to assume that, for example, in the case of academic performance, practicing meditation could produce differential effects on the subjects depending on the type of cognitive skills they demand. It would also be interesting to compare the efficacy of different meditation techniques, and to find out which technique or program is best for a type of variable or cognitive skill. This way, meditation programs could be adapted to the educational environment with precise goals, such as academic performance. Another matter of capital importance which also requires future research, is finding out the differential effects that the various components of a meditation program like this one have, isolating those responsible for change and discarding those that are not.

Finally, we consider that although the results of this study were positive, precaution should be used in their generalization, since the study sample can be considered relatively small. The long-term permanence of the results must also be confirmed with follow-up studies that verify whether the academic performance, self-concept and anxiety levels are maintained over time.

\section{REFERENCES}

Arias, A. J., Steinberg, K., Banga, A., \& Trestman, R. L. (2006). Systematic review of the efficacy of meditation techniques as treatments for medical illness. Journal of Alternative and Complementary Medicine (New York, N.Y.), 12(8), 817-832. doi:10.1089/acm.2006.12.817

Austin, J. H. (1998). Zen and the Brain. Cambridge, MA: MIT Press.

Baer, R. (2003). Mindfulness training as a clinical intervention: A conceptual and empirical review. Clinical Psychology: Science and Practice, 10(2), 125-142. doi:10.1093/clipsy/bpg015

Barnes, V. A., Bauza, L. B., \& Treiber, F. A. (2003). Impact of stress reduction on negative school behavior in adolescents. Health and Quality of Life Outcomes, 1(10), 5-30.

Barnes, V. A., Treiber, F. A., \& Davis, H. (2001). Impact of transcendental meditation in cardiovascular function at rest and during acute stress in adolescents with high normal blood pressure. Journal of Psychosomatic Research, 51(4), 597-605. doi:10.1016/ S0022-3999(01)00261-6

Barragán, R., Lewis, H., \& Palacio, J. E. (2007). Autopercepción de cambios en los déficit atencionales intermedios de estudiantes universitarios de Barranquilla sometidos al método de autocontrol de la atención (mindfulness) [Auto-perception of the changes in the intermediary attention deficits of university students in Barranquilla submitted to the attention self-control mindfulness method]. Salud Uninorte, 23, 184-192. 
Beaucheim, J., Hutchins, T., \& Patterson, F. (2008). Mindfulness meditation may lessen anxiety, promote social skills, and improve academic performance among adolescents with learning disabilities. Complementary Health Practice Review, 13(1), 34-45. doi:10.1177/1533210107311624

Bishop, S. R., Lau, M., Shapiro, S., Carlson, L., Anderson, N., \& Cardomy, J. (2004). Mindfulness: A proposed operational definition. Clinical Psychology: Science and Practice, 10,230-241.doi:10.1093/ clipsy/bph077

Blackledge, J. T. (2007). Disrupting verbal processes: cognitive defusion in acceptance and commitment therapy and other mindfulness-based psychotherapies. The Psychological Record, 57, 555-576.

Brefczynski-Lewis, J. A., Lutz, A., Schaefer, H. S., Levinson, D. B., \& Davidson, R. J. (2007). Neural correlates of attentional expertise in long-term meditation practitioners. Proceedings of the National Academy of Sciences of the United States of America, 104, 11483-11488. doi:10.1073/pnas.0606552104

Brown, K. W., \& Ryan, R. M. (2003). The benefits of being present: Mindfulness and its role in psychological well-being. Journal of Personality and Social Psychology, 84, 822-848. doi:10.1037/00223514.84.4.822

Brown, K. W., Ryan, R. M., \& Creswell, J. D. (2007). Mindfulness: theoretical foundations and evidence for its salutary effects. Psychological Inquiry, 18, 211-227.

Camero, F., Martín, F., \& Herrero, J. (2000). Estilos y estrategias de aprendizaje en estudiantes universitarios [Styles and learning strategies in university students]. Psicothema, 12(4), 615-622.

Campagne, D. M. (2004). Teoría y fisiología de la meditación [Theory and physiology of meditation]. Cuadernos de Medicina Psicosomática y Psiquiatría de Enlace, 69/70, 15-30.

Carbonero, I. (1999). Ansiedad y rendimiento académico [Anxiety and academic performance]. Punto y Aparte, 7, 123-136.

Chang, J., \& Hierbert, B. (1989). Relaxation procedures with children:Areview. Medical Psycotherapy: An International Journal, 22, 163-173.

Corbière, M., Fraccaroli, F., Mbekou, V., \& Perron, J. (2006).Academic self-concept and academic interest measurement: A multi-sample European study. European Journal of Psychology of Education, 21(1), 3-15. doi:10.1007/BF03173566
Cranson, R. W., Orme-Johnson, D. W., Gackenbach, J., Dillbeck, M. C., Jones, C. H., \& Alexander, C. N. (1991). Transcendental meditation and improved performance on intelligence-related measures: A longitudinal study. Personality and Individual Differences, 10, 1105-1116. doi:10.1016/01918869(91)90040-I

Davidson, R. J., Kabat-Zinn, J., Schumacher, J., Roserkranz, M. S., Muller, D., \& Santorelli, S. F. (2003). Alterations in brain and immune function produced by Mindfulness. Psychosomatic Medicine, 65 , 564-570. doi:10.1097/01.PSY.0000077505.67574. E3

Del Barrio, V. (1997). Depresión infantil: Concepto, evaluación y tratamiento [Infant depression: Concept, evaluation and treatment]. Barcelona, Spain: Ariel.

Deshimaru, T. (2006). La práctica del Zen [The practice of Zen]. Barcelona, Spain: RBA.

Dunn, B. R., Hartigan, J. A., \& Mikulas, W. L. (1999). Concentration and mindfulness meditations: Unique forms of consciousness? Applied Psychophysiology and Biofeedback, 24, 147-165. doi:10.1023/A:1023498629385

Epply, K. R., Abraham, A. I., \& Shear, J. (1989). Differential effects of relaxation techniques on trait anxiety: A meta-analysis. Journal of Clinical Psychology, 45, 957-974. doi:10.1002/1097-4679(198911)45:6<957::AIDJCLP2270450622>3.0.CO;2-Q

Franco, C. (2007). Técnicas de relajación y desarrollopersonal [Relaxation and personal development techniques]. Granada: Cepa.

Franco, C. (2009a). Meditación Fluir para serenar el cuerpo y la mente [Meditación Fluir for tranquilizing body and mind]. Madrid, Spain: Bubok.

Franco, C. (2009b). Reducción de la percepción del estrés en estudiantes de Magisterio meditante la práctica de la Meditación Fluir [Reducing stress perception in students of teacher education through the practice of Meditación Fluir]. Apuntes de Psicología, 27(1), 99-109.

Franco, C. (in press). Efectos de un programa de meditación sobre los niveles de creatividad verbal de un grupo de alumnos de Bachillerato [Effects of a meditation program on verbal creativity levels in a group of high school students]. Suma Psicológica. 
Franco, C., \& Mañas, I. (2009). Reducción de los niveles de estrés docente y de los días de baja laboral por enfermedad en profesores de educación secundaria obligatoria a través de un programa de entrenamiento en meditación [Reducing levels of educational stress and of the days taken off work on sick leave, in teachers of obligatory secondary education by means of a meditation training programme].

Franco, C., Mañas, I., Cangas, A., Moreno, E., \& Gallego, J. (in press). Reducing of psychological distress in teachers by a mindfulness training programme. The Spanish Journal of Psychology.

Franco, C., \& Navas, M. (in press). Efectos de un programa de meditación sobre los valores de una muestra de estudiantes universitarios [Effects of a meditation program on values in a sample of university students]. Electronic Journal of Research in Educational Psychology.

Germer, C. K., Siegel, R. D., \& Fulton, P. R. (2005). Mindfulness and psychotherapy. New York, NY: Guilford Press.

Goleman, D. (2003). Destructive emotions and how we can overcome them. London, UK: Bloomsbury Publishing.

González-Pienda, J. A., Núñez, J. C., GonzálezPumariega, S., Álvarez, L., Roces, C., \& García, M. (2002). A structural equation model of parental involvement, motivational and aptitudinal characteristics, and academia achievement. Journal of Experimental Education, 70(3), 257-287. doi:10.1080/00220970209599509

Grossman, P., Niemann, L., Schmidt, S., \& Walach, H. (2004). Mindfulness-based stress reduction and health benefits: A meta-analysis. Journal of Psychosomatic Research, 57, 35-43. doi:10.1016/ S0022-3999(03)00573-7

Hart, W. (1994). La Vippasana. El arte de la meditación [Vippasana. The art of meditation]. Madrid, Spain: Luz de Oriente.

Hayes, A. M., \& Feldman, G. (2004). Clarifying the construct of mindfulness in the context of emotion regulation and the process of change in therapy. Clinical Psychology: Science and Practice, 11(3), 255-262. doi:10.1093/clipsy/bph080

Hayes, S. C., Follette, V. M., \& Linehan, M. M. (2004). Mindfulness and acceptance: Expanding the cognitive behavioral tradition. New York, NY: Guilford Press.
Hayes, S. C., Luoma, J. B., Bond, F. W., Masuda, A., \& Lillis, J. (2006). Acceptance and commitment therapy: model, processes and outcomes. Behaviour Research and Therapy, 44, 1-25. doi:10.1016/j. brat.2005.06.006

Hayes, S. C., \& Strosahl, K. D. (2004). A practical guide to acceptance and commitment therapy. New York, NY: Springer-Verlag.

Hayes, S. C., Stroshal, K. D., \& Wilson, K. G. (1999). Acceptance and commitment therapy. New York, NY: Guilford Press.

Jacobs, G. D., Benson, H., \& Fierdman, R. (1993). Home-based central nervous system assessment of a multifactor behavioural intervention for chronic sleep-onset insomnia. Behavior Therapy, 24, 159174. doi:10.1016/S0005-7894(05)80261-8

Jevning, R. (1988). Integrated metabolic regulation during states of decreased metabolism, similarity to fasting: A biochemical hypothesis. Physiology \& Behavior, 43, 735-737. doi:10.1016/00319384(88)90370-8

Jevning, R., Anand, R., Biedebach, M., \& Fernando, G. (1996). Effects on region cerebral blood flow of transcendental meditation. Physiology \& Behavior, 59(3),399-402. doi:10.1016/0031-9384(95)02006-3

Jha, A. P., Krompinger, J., \& Baime, M. J. (2007). Mindfulness training modifies subsystems of attention. Cognitive, Affective \& Behavioral Neuroscience, 7, 109-119. doi:10.3758/CABN.7.2.109

Kabat-Zinn, J. (1990). Full Catastrophe Living: using the wisdom of your body and mind to face stress, pain, and illness. New York, NY: Dell Publishing.

Kabat-Zinn, J. (1994). Where you go there you are. New York, NY: Hyperion.

Kabat-Zinn, J., Massion, A. O., Kristeller, J., Peterson, L. G., Fletcher, K. E., \& Pbert, L. (1992). Effectiveness of a meditation-based stress reduction program in the treatment of anxiety disorders. The American Journal of Psychiatry, 149, 936-943.

León, B. (2008). Atención plena y rendimiento académico en estudiantes de educación secundaria [Mindfulness and academic performance in secondary education students]. European Journal of Education and Psychology, 1(3), 17-26.

LeShan, L. (2005). Cómo meditar [How to meditate]. Barcelona, Spain: Kairós. 
Liu, X., Kaplan, H. B., \& Risser, W. (1992). Decomposing the reciprocal relationships between academia achievement and general self-stem. Youth \& Society, 24, 123-148. doi:10.1177/0044118X92024002001

MacLean, R. K., Walton, K. G., Wenneberg, S. R., Levitsky, D. K., Mandarino, J. P., \& Waziri, R. (1994). Altered responses of cortisol, GH, TSH and testosterone to acute stress after four months' practice of Transcendental Meditation (TM). Annals of the New York Academy of Sciences, 746, 381-384. doi:10.1111/j.1749-6632.1994.tb39261.x

Mañas, I., Luciano, M. C., \& Sánchez, L. C. (2008). Beginners practising a basic mindfulness technique: An experimental analysis. Paper presented at the $4^{\text {th }}$ Conference of the European Association for Behaviour Analysis, Madrid, Spain.

Mañas, I., Sánchez, L. C., \& Luciano, M. C. (2008, April). Effects of a mindfulness exercise (body-scan): A pilot study. Paper presented at the 7th Congress of the Spanish Society of Experimental Psychology, San Sebastián-Donostia, Spain.

Marsh, H. W. (1990). A multidimensional, hierarchical self-concept: Theoretical and empirical justification. Educational Psychology Review, 2, 77-172. doi:10.1007/BF01322177

Mestre, V. (1992). La depresión en población adolescente valenciana [Depression in a teenage population in Valencia]. Valencia, Spain: Consejería de Sanidad y Consumo.

Millar, R. B., Behrens, J. T., \& Greene, B. A. (1993). Goals and perceived ability: Impact on student valuing, self-regulation and persistence. Contemporary Educational Psychology, 18, 2-14. doi:10.1006/ ceps.1993.1002

Musitu, G., García, F., \& Gutiérrez, M. (1994). Cuestionario de Autoconcepto Forma A [Self-Concept Questionnaire: Form A]. Madrid, Spain: TEA.

Núñez, J. C., González-Pienda, J. A., García, M., González-Pumariega, S., Roces, C., \& Álvarez, L. (1998). Estrategias de aprendizaje, autoconcepto y rendimiento académico [Learning strategies, selfconcept and academic achievement]. Psicothema, 10(1), 97-109.

Núñez, J. C., González-Pienda, J. A., García, M. S., González-Pumariega, S., \& García, S. I. (1995). Estrategias de aprendizaje en estudiantes de 10 a 14 años y su relación con los procesos de atribución causal, el autoconcepto y las metas de estudio [Learning strategies for students from 10 to 14 years old and their relationships to causal attribution, self-concept and study goals]. Revista Galega de Psicopedagogía, 10/11, 219-242.
Pérez, M. A., Martín, A., Borda, M., \& Del Río, C. (2003). Estrés y rendimiento académico en estudiantes universitarios [Stress and academic performance in university students]. Cuadernos de Medicina Psicosomática y Psiquiatría de Enlace, 67/68, 26-33.

Rains, D. (2004). Principios de neuropsicología humana [Principles of human neuropsychology]. New York, NY: McGraw-Hill.

Rial, A., \& Valera, J. (2008). Estadística práctica para la investigación en ciencias de la salud [Practical statistics for investigation in health sciences]. A Coruña, Spain: Netbiblo.

Rivas, F. (1997). El proceso de enseñanzalaprendizaje [The teaching/learning process]. Barcelona, Spain: Ariel Planeta.

Roberts, R. L., Sarigiani, P. A., Petersen, A. C., \& Newman, J. L. (1993). Gender differences in the relationship between achievement and self-image during early adolescence. In Pierce, R. A., \& Black, M. A. (Eds.), Life span development (pp. 126-139). Dubuque, IA: Kendall.

Skaalvik, E. M., \& Hagtvet, K. A. (1990). Academic achievement and self-concept: An analysis of causal predominance in a developmental perspective. Journal of Personality and Social Psychology, 58, 292-307. doi:10.1037/0022-3514.58.2.292

Solberg, E. E., Berglund, K. A., Engen, O., Ekeberg, O., \& Loeb, M. (1996). The effect of meditation on shooting performance. British Journal of Sports Medicine, 30(4), 342-346. doi:10.1136/bjsm.30.4.342

Solberg, E. E., Halvorsen, R., \& Holen, A. (2000). Effect of meditation on immune cells. Stress Medicine, 16, 185-190. doi:10.1002/(SICI)10991700(200004)16:3<185::AID-SMI852>3.0.CO;2-C

Solberg, E. E., Halvorsen, R., Sundgot-Borgen, J., Ingier, F., \& Holen, A. (1995). Meditation: A modulator of the immune response to physical stress. British Journal of Sports Medicine, 29(4), 255-257. doi:10.1136/bjsm.29.4.255

Spielberger, C. D., Gorsuch, R. L., \& Lushene, R. E. (1988). Cuestionario de Ansiedad Estado-Rasgo (STAI) [State-Trait Anxiety Inventory (STAI)]. Madrid, Spain: TEA.

Sudsuang, R. (1991). Effect of Buddhist meditation on serum cortisol and total protein levels, blood pressure, pulse rate, lung volume and reaction time. Physiology \& Behavior, 50(3), 543-548. doi:10.1016/0031-9384(91)90543-W 
Sugiura, Y. (2004). Detached mindfulness and worry: a meta-cognitive analysis. Personality and Individual Differences, 37, 169-179. doi:10.1016/j. paid.2003.08.009

Teasdale, J., Segal, Z., \& Williams, J., Ridgeway, Soulsby, J., \& Lau, M. (2000). Prevention of relapse/ recurrence in mayor depression by mindfulness-based cognitive therapy. Journal of Consulting and Clinical Psychology, 68(4), 615-623. doi:10.1037/0022006X.68.4.615

Trumbulls, M. J., \& Norris, H. (1982). Effects of Transcendental Meditation on self identity indices and personality. The British Journal of Psychology, 73, 57-68.
Valentine, E. R., \& Sweet, P. L. (1999). Meditation and attention: A comparison of the effects of concentrative and mindfulness meditation on sustained attention. Mental Health, Religion \& Culture, 2, 59-70. doi:10.1080/13674679908406332

Van der Berg, W. P., \& Mulder, B. (1976). Psychological research on the effects of the transcendental meditation technique on a number of personality variables. Gedrag: Tijdschrift voor Psychologie, 4, 206-218. 